\title{
Relapsed clubfoot correction with soft-tissue release and selective application of Ilizarov technique
}

\author{
Konstantinos N. Malizos • Nikolaos E. Gougoulias • \\ Zoe H. Dailiana $\cdot$ Nikolaos Rigopoulos • \\ Theofanis Moraitis
}

Received: 11 June 2008/Accepted: 21 November 2008/Published online: 5 December 2008

(C) Springer-Verlag 2008

\begin{abstract}
The Ilizarov technique is an alternative for the treatment of complex foot deformities in children. The authors retrospectively reviewed children with relapsed clubfoot deformity, treated with soft tissue procedures and additional correction with an Ilizarov frame. Twelve consecutive patients (13 feet) with relapsed clubfoot deformity after previous surgical correction were reviewed. Treatment included open releases. An Ilizarov frame was applied as an adjunct in seven patients (mean age of 7.8 years) with severe deformity where complete intraoperative correction was not achieved. Clinical and radiographic assessment was undertaken. The mean Laaveg-Ponseti score, for the 7 feet treated with the Ilizarov frame, was 85.1 after minimum 4 years follow-up. One recurrence of forefoot deformity required metatarsal osteotomies. Postoperative radiographic measurements revealed values that can be considered as normal. Complications included pin tract infections (12\% of inserted wires). Flat-topped talus was observed in 3 feet. Deformity correction was possible when soft tissue procedures were combined with the use of Ilizarov technique, in order to support and gradually improve surgical correction.
\end{abstract}

Keywords Clubfoot - Ilizarov $\cdot$ Recurrent $\cdot$ Relapsed · Release

K. N. Malizos $(\bowtie) \cdot$ N. E. Gougoulias ·

Z. H. Dailiana · N. Rigopoulos - T. Moraitis

Department of Orthopaedic Surgery, University of Thessalia,

22 Papakiriazi St, 41222 Larissa, Greece

e-mail: malizos@med.uth.gr

\section{Introduction}

Clubfoot in the neonates is a complex foot deformity including equinus, hindfoot varus, forefoot adductus, and sometimes pes cavus. The idiopathic form presenting as congenital talipes equinovarus (CTEV), is a common congenital foot deformity occurring in one to three per thousand live births and is related to multi-factorial inheritance [1-3]. Other causes of clubfoot include arthrogryposis, spasticity, Charcot-Marie-Tooth disease, meningomyelocele and encephalitis [1].

The aim of treatment of the clubfeet is to obtain fully corrected, mobile, plantigrade feet at maturity, walking comfortably with normal shoes. However, even with surgical management, individuals may present with some residual deformity and may suffer from a recurrence requiring further surgery in about $20 \%$ of cases [4]. Multiple operations, however, often result in a stiff, small and painful foot [5, 6]. Moreover, when surgical treatment involves bone procedures the foot is further shortened. An alternative treatment method is gradual distraction with or without soft-tissue release or bony distraction following an osteotomy and using the Ilizarov technique.

During the last two decades, the Ilizarov technique has been used increasingly in the treatment of complex resistant clubfoot deformities in children [7-23]. Ilizarov showed that both soft tissue and bone are amenable to lengthening by distraction histogenesis [7]. The Ilizarov technique involves placing tension wires through the bony structures of the clubfoot to realign the joint surfaces and foot anatomy in all three planes [7, 10, 11, 15, 17]. Depending on the severity of the deformity and the patient's age the Ilizarov technique can be combined with posteromedial soft tissue releases, tendon lengthening and osteotomies if necessary $[10,17,24]$, to avoid acute 
correction often associated with soft tissue healing problems and neurovascular complications [7, 10].

In this study, we retrospectively reviewed patients with relapsed clubfoot deformity treated with soft tissue procedures and additional correction with the Ilizarov frame.

\section{Materials and methods}

This is a retrospective analysis of patients with relapsed clubfoot deformity after initial surgical correction. Twelve consecutive patients (13 feet), 9 boys and 3 girls, were included. Congenital talipes equinovarus (CTEV) was the diagnosis in 10 feet ( 9 patients), paralytic clubfoot in one (posttraumatic sciatic nerve palsy with complete tibial and incomplete peroneal nerve recovery), whereas meningomyelocele and encephalomyelitis shortly after birth were the causative conditions in the remaining two cases. Eleven patients (12 feet) were skeletally immature. Three children had bilateral deformities, the contralateral side requiring further surgical treatment in one boy. Eleven feet had one previous operation, while two feet had two prior procedures (average $1.2 \pm 0.4$ ). All previous operations consisted of soft tissue releases. Ten (11 treated feet) of 12 patients were referrals. All patients underwent further surgical treatment by the same group of surgeons. Seven patients (7 feet) required the addition of a circular frame for gradual skeletal postoperative correction, whereas in 6 feet the correction was completed acutely and stabilized with Kirschner wires (K-wires). The use of an Ilizarov frame depended on the surgeon's judgment intraoperatively, of the degree of correction achieved after soft tissue releases were completed. Involvement of both hindfoot and forefoot and a stiff deformity, hardly correctable passively to any degree, and/or resistant intraoperative deformity after soft tissue releases were indications for an Ilizarov frame application, so to gradually improve and maintain correction, in children older than 3 years of age.

Soft tissue releases were always performed using loops magnification $(\times 4.5)$. An extended posteromedial incision was used, often in line with a previous posteromedial incision. The posterior tibial neurovascular bundle was identified and dissected free of scar. The tibialis posterior (TP), flexor digitorum longus (FDL) and flexor hallucis longus (FHL) tendons were isolated along the entire length of the incision. The Achilles tendon was approached medially and in most cases, scaring was present between the Achilles tendon sheath and Achilles tendon itself. Posterior and medial dissection allowed visualization of the posteromedial aspects of the ankle joint, subtalar joint, and the medial and plantar and dorsal aspect of the talonavicular, navicular-cuneiforn and first tarsometatarsal joints. Complete release by capsulotomies of the ankle, subtalar, talonavicular and first tarsometatarsal joints until mobilization of the ankle, hindfoot, and midfoot was obtained. In all cases, irrespective of the presence of a cavus deformity, a plantar fascia release was performed near its origin. Flexor digitorum brevis and hallux abductus muscles were also released from their proximal insertions to allow forefoot correction. The ankle joint posterior capsule release was necessary to correct hindfoot equinus. Medial releases were used to correct varus of the hindfoot and adduction of the midfoot. Calcaneocuboid release was used in two cases to realign the lateral border of the foot. After the release had been completed, the foot and the ankle were partially corrected and the Achilles, TP, FHL and FDL tendons were lengthened and repaired.

The Ilizarov frame (Smith and Nephew, Memphis, Tennessee) was applied after the completion of soft tissue releases and closure of the surgical incisions in seven cases with a mean age of 7.8 years (range 3-17). In all these cases, the relapsed deformity was not correctable passively at the end of the soft tissue release/lengthening procedure.

The frame consisted of two tibial rings and a half ring placed posterior and fixed on to the calcaneus (Fig. 1). Another half-ring for transfixion of the anterior and midfoot completed the frame configuration. Crossed $1.5 \mathrm{~mm}$ wires tensioned at $70 \mathrm{~kg}$, were used to fix the rings. The tibial rings were placed in the mid- and distal tibia with either half-pins or tensioned wires. A hinged construct was used for equinus correction, as reported also by other authors [18]. Distractors connected the calcaneal and tibial rings to allow for correction of equinus and varus sequentially (Fig. 1). The midfoot ring distractors were positioned so that the equinus, supination, and adduction could be corrected. Additional distractors, placed medially

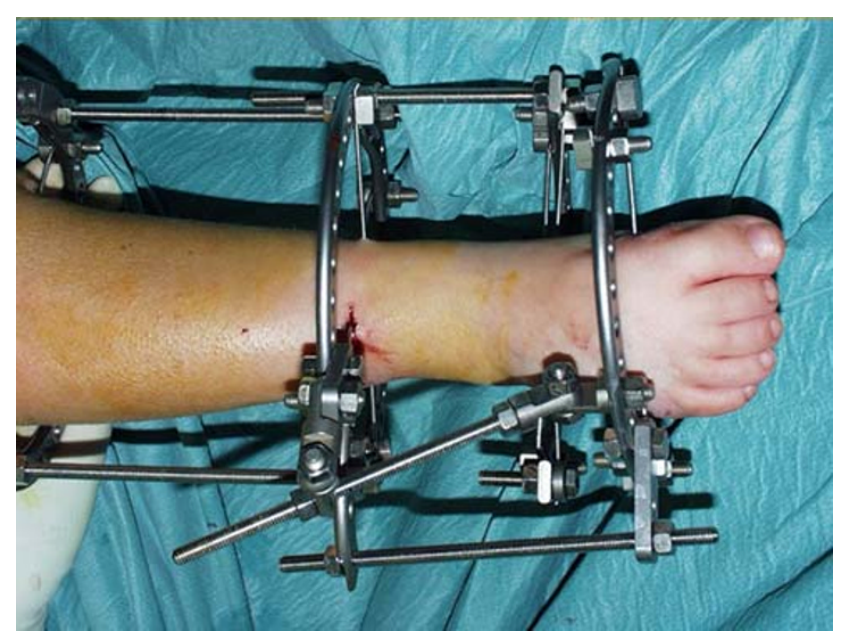

Fig. 1 The Ilizarov frame (Smith and Nephew, Memphis, Tennessee) consisted of two tibial rings, a half ring placed posterior and fixed on to the calcaneus and a midfoot transfixion half-ring. Hinges placed appropriately allowed gradual correction 
and laterally between the metatarsal and calcaneal halfrings, were applied to correct residual cavus. The hindfoot deformity was corrected by lengthening the two rods connecting the tibial segment to the hindfoot fixator segment. The medial rod was lengthened faster than the lateral one to obtain simultaneous correction of the varus deformity. Adduction and cavus deformities of the midfoot and forefoot were corrected by lengthening the rods that connected the hindfoot to the forefoot. Equinus deformity was the last to be corrected. Distraction and gradual correction started 2 days following surgery and lasted until some overcorrection was obtained. Normal weight bearing mobilization was allowed at the child's tolerance, when a plantigrade foot was achieved. The frame remained in situ for 9-12 weeks depending on the severity of the deformity and the degree of stiffness. The frame was then removed under sedation anesthesia and a below knee walking cast was applied for 6 weeks. Night splints were used thereafter for 6 months. In the other subset of 6 feet, the K-wires were removed in the eighth week followed by application of a walking cast ( 6 weeks). Night splints were used thereafter for 6 months.

In the remaining five patients (6 feet) percutaneous $\mathrm{K}$-wires, from the calcaneus to the subtalar and ankle joints and across the first metatarsal—-talus axis were used after defining an appropriate corrective position. Three of these children (4 feet) were younger than 3 years old when revision surgery was performed and although two of them ( 2 feet) presented with stiff deformities, application of an Ilizarov frame would be inappropriate for their age. One 4-year-old boy presented with a fully correctable hind- and forefoot deformity after open soft tissue releases. A 7-year-old boy with learning difficulties (premature birth) presented with a stiff hind- and forefoot deformity. Primary cause was posttraumatic sciatic nerve palsy. Previously ( 8 months old) he has had a tibialis anterior transfer. The option of an Ilizarov frame application was discussed with his parents preoperatively, but was not chosen because of the patient's mental health deficiency and care difficulties.

Patients were evaluated according to the following clinical criteria: foot and ankle shape and alignment (heel varus or valgus malalignment), pain, range of motion, capacity to walk, ability to wearing conventional shoes, absence of significant recurrence of the original deformity and parents' satisfaction with the final appearance and function of the leg. Whenever the patient's age did not allow reliable subjective measurement of pain and evaluation of activities and walking ability, the parents' opinion was considered instead. The results were quantified according to the Laaveg and Ponseti functional rating system [25]. Radiographic measurements included angle measurements on the anteroposterior (talo-calcaneal, talar1st metatarsal and calcaneal-5th metatarsal angles) and lateral views (talo-calcaneal angle). Foot and ankle anteroposterior and lateral radiographs were taken with ankle in dorsiflexion. Both clinical and radiographic evaluation for research purposes was undertaken by an independent examiner, other than the surgeons.

Student's $T$ test was applied to compare pre- and postoperative values of radiographic measurements. Level of statistical significance was set at 0.05 .

Table 1 Summary of patients data, surgical procedures and outcomes

\begin{tabular}{|c|c|c|c|c|c|c|c|c|}
\hline & Gender & Cause & $\begin{array}{l}\text { Age 1st procedure } \\
\text { (months) }^{\mathrm{a}}\end{array}$ & $\begin{array}{l}\text { Age 2nd procedure } \\
\text { (years) }^{\mathrm{b}}\end{array}$ & $\begin{array}{l}\text { Ilizarov } \\
\text { frame }\end{array}$ & $\begin{array}{l}\text { Time in frame } \\
\text { (weeks) }\end{array}$ & $\begin{array}{l}\text { Follow-up } \\
\text { (months) }\end{array}$ & $\begin{array}{l}\text { Laaveg-Ponseti } \\
\text { score }\end{array}$ \\
\hline 1 & M & CTEV & 4 & 4 & No & NA & 60 & 96 \\
\hline 2 & M & EM & 12 & 12 & Yes & 9 & 52 & 77 \\
\hline 3 & $\mathrm{~F}$ & CTEV & 12 & 17 & Yes & 12 & 54 & 82 \\
\hline 4 & $\mathrm{~F}$ & CTEV & 6 & 1.5 & No & NA & 48 & 81 \\
\hline 5 & M & CTEV & 6 & 5 & Yes & 10 & 48 & 97 \\
\hline 6 & M & CTEV & 5 & 2.5 & No & NA & 64 & 96 \\
\hline 7 & M & CTEV & 7 & 3 & Yes & 8 & 84 & 86 \\
\hline 8 & M & CTEV & 14 & 3 & Yes & 13 & 64 & 83 \\
\hline 9 & M & CTEV & 3 & 10 & Yes & 12 & 64 & 98 \\
\hline 10 & $\mathrm{~F}$ & MMC & 24 & 4.5 & Yes & 12 & 64 & 73 \\
\hline $11 \mathrm{R}$ & M & CTEV & 12 & 2.5 & No & NA & 30 & 88 \\
\hline $11 \mathrm{~L}$ & M & CTEV & 12 & 2.5 & No & NA & 30 & 84 \\
\hline 12 & M & PAR EQCV & 8 & 7 & No & NA & 24 & 86 \\
\hline
\end{tabular}

$R$ right, $L$ left, $M$ male, $F$ female, $M M C$ meningomyelocele, $E M$ encephalomyelitis, $P A R$ paralytic, $E Q C V$ equinocavovarus, $N A$ non-applicable

${ }^{a}$ Age 1: Age at initiation of surgical treatment (months)

b Age 2: Age at treatment of relapsed deformity (years) 


\section{Results}

The patients had their first surgical intervention to correct the clubfoot deformity at a mean age of 9.6 months (range 3-24 months). They were treated for their relapsed deformity at a mean age of 5.7 years (range 1.5-17 years) and followed for a mean of 52.8 months (24-84 months). The 7 patients ( 7 feet) treated with the Ilizarov technique as an adjunct for deformity correction, had a mean age at first surgical correction of $11.1 \pm 6.9$ months (range 3-24) and a mean age at correction of the relapsed deformity of

Table 2 Clinical outcome according to the Laaveg-Ponseti scale

\begin{tabular}{llll}
\hline Score & Total (13) & Ilizarov (7) & K-wires (6) \\
\hline Excellent (90-100 points) & 4 & 2 & 2 \\
Good (80-89 points) & 7 & 3 & 4 \\
Fair (70-79 points) & 2 & 2 & 0 \\
Poor (<70 points) & 0 & 0 & 0 \\
\hline
\end{tabular}

$7.8 \pm 5.4$ years (range 3-17). The external ring-fixator remained in situ for a mean of 11.4 weeks (range 9-13). They underwent 1.1 (range 1-2) previous surgical corrections and were followed for at least 4 years (mean 63.7 months). The mean Laaveg-Ponseti score for the 13 feet was $86.7 \pm 8.0$ (range 73-96) and the result was considered excellent in 4 feet, good in 7 and fair in 2, whereas the mean score for the 7 feet treated with addition of the Ilizarov frame was 85.1 ( 2 excellent, 3 good, 2 fair results) (Tables 1, 2).

Both cases with a fair result were children with neurologic disorders (encephalomyelitis and meningomyelocele) severely affecting their walking ability and gait, despite good alignment and correction. All other patients had normal activities compared to children of their age and all were able to wear conventional shoes. Maximal foot length in 9 patients with unilateral involvement was $6.7 \%$ (range 3.3-8.9) shorter than the contra-lateral healthy side, at the final follow-up. Maximum calf circumference in the same
Fig. 2 Pre- and postoperative radiographic angle measurements for each patient
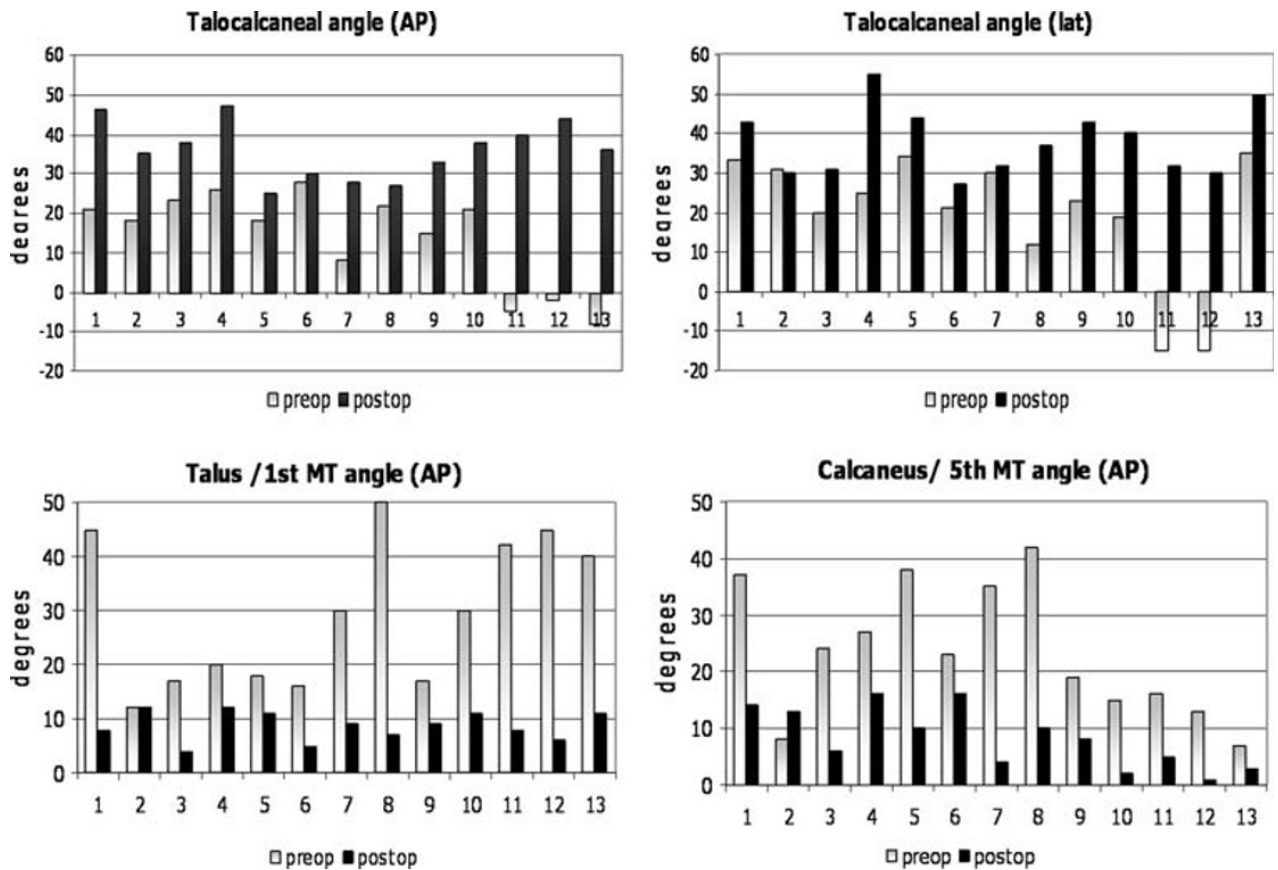

Table 3 Radiographic parameters (mean values) at final follow-up, in 7 stiff feet requiring an Ilizarov frame

$M T$ metatarsal, $A P$ anteroposterior, lat lateral, stdev standard deviation

Significant differences were obtained between pre- and postoperative values

\begin{tabular}{lcllc}
\hline & $\begin{array}{l}\text { Talo-calcaneal } \\
(\text { AP) }\end{array}$ & $\begin{array}{l}\text { Talus- 1st MT } \\
(\text { AP })\end{array}$ & $\begin{array}{l}\text { Calcaneus- 5th MT } \\
(\text { AP) }\end{array}$ & $\begin{array}{l}\text { Talo-calcaneal } \\
\text { (lat) }\end{array}$ \\
\hline Preop. & & & & 24.1 \\
Mean & 17.9 & 24.9 & 25.9 & 7.9 \\
Stdev & 5.1 & 13.0 & 12.8 & \\
Postop. & & & & 36.7 \\
Mean & 32.0 & 9.0 & 7.6 & 5.8 \\
Stdev & 5.4 & 2.8 & 3.8 & 0.01 \\
$P$ value & $<0.001$ & 0.02 & 0.01 & \\
\hline
\end{tabular}


Fig. 3 Relapsed stiff clubfoot deformity (a) required soft tissue releases (b) combined with application of an Ilizarov frame (c) at the age of 3 years. Forefoot deformity recurrence (d) at the age of 6 years required proximal metatarsal osteotomies. Good alignment is maintained at the age of 10 years $(\mathbf{e}-\mathbf{i})$. Flat topped talus on the lateral radiograph (f)
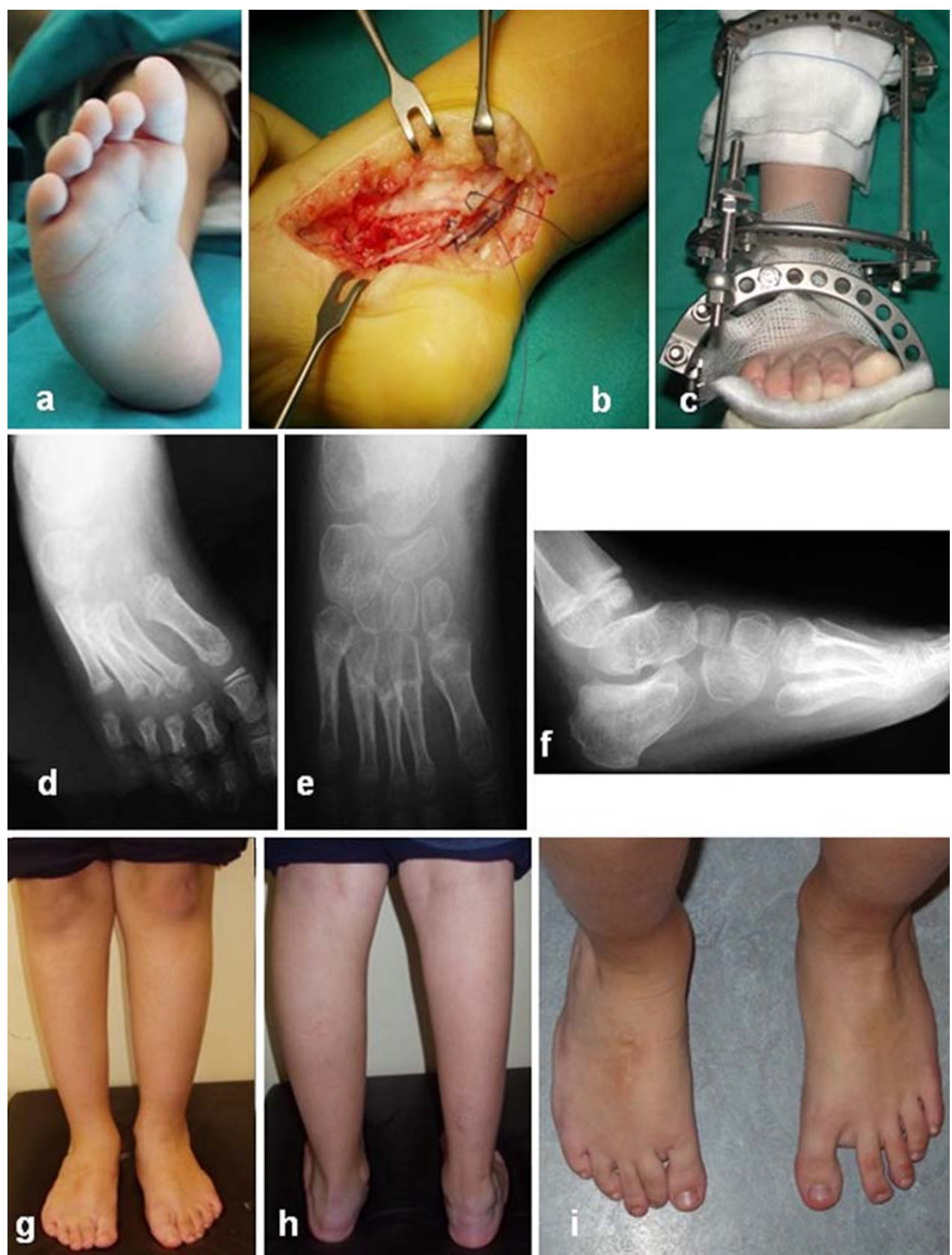

subgroup was $11.4 \%$ (range 5.6-14) shorter, respectively. The respective values for the 6 unilaterally affected relapsed clubfeet treated with an Ilizarov frame were $3.2 \%$ (range 3.3-7.8\%) shorter maximal foot length and $8.7 \%$ (range 5.6-10.5\%) shorter maximal calf circumference.

Although standing radiographs should be obtained [26], standardized radiographic views were not always possible due to the young age of most of the patients. Radiographic measurements significantly improved after treatment as shown in Fig. 2 and Table 3 and postoperative measurements revealed values that can be considered as normal $[1,26]$.
Complications included pin tract infections (12\% of inserted wires), all resolving with local care. A flat-topped talus (Fig. 3f) was observed in 3 feet (Table 1, patients 3, 7, 8). Talonavicular subluxation, distal tibia epiphysiolysis, or claw-toe deformities were not observed. External fixator intolerance was not reported by any of the patients or their parents.

Recurrence of forefoot adduction occurred in one patient (case 7) 36 months after correction using an Ilizarov frame. He underwent open arthrolysis of the midtarsal joints, however, stiffness prevented full correction. Thus, proximal metatatarsal osteotomies were undertaken and a 
Fig. 4 Asymptomatic, wellaligned foot in a teenager after soft tissue release and Ilizarov frame application. The left foot (arrows), initially surgically treated at the age of 3 , underwent surgical treatment for relapse of his clubfoot at the age of 10 years (open arthrolysis, Achilles, FHL, FDL tendon lengthening and plantar aponeurosis release accompanied by an Ilizarov frame), achieving a LaavegPonseti score of 98 after 4.5 years of follow-up
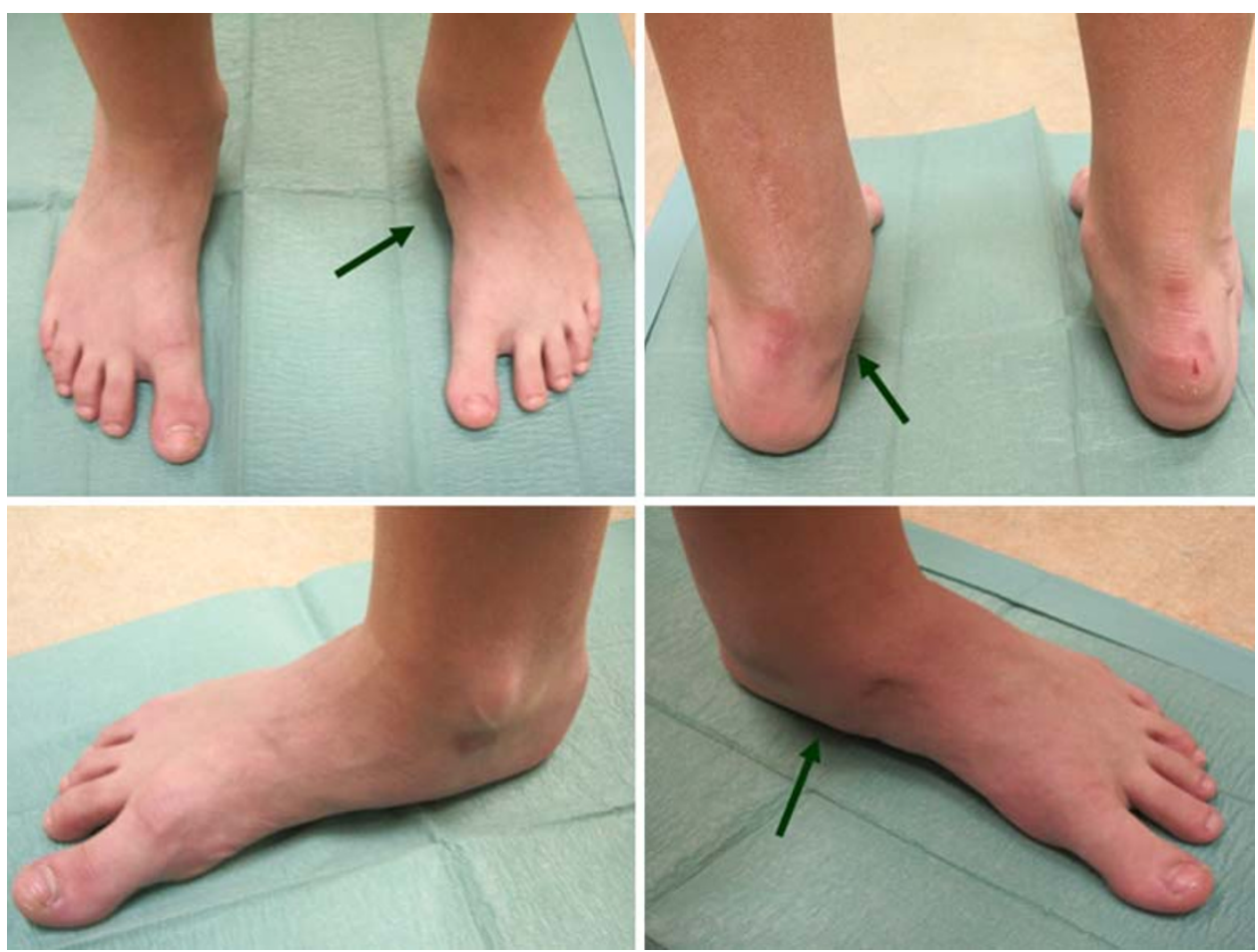

well-aligned, painless foot has been maintained up to the final 48 months follow-up at the age of 9 years (Fig. 3).

\section{Discussion}

Controversy regarding the best treatment of congenital clubfoot has been present for 2,500 years, with Hippocrates proposing treatment with manipulation and splinting [4]. Excellent or good results with extensive surgical releases, after unsuccessful manipulation and casting techniques, have been achieved in 52-91\% of cases in the short term [27-29]. Even successful surgery can result in a shortened foot and the result may be unsatisfactory $[5,6,10]$. Longterm studies showed that recurrence commonly occurs, stiffness and ankylosis appears and arthritis of the hindand midfoot joints, often requires arthrodesis [5, 6, 28, 30].

Scar tissue after repeated soft tissue release makes correction difficult but possibly manageable with the Ilizarov technique $[10,17-20,22,24]$. According to Paley's concept [10,11, 22, 24], deformity correction can occur without a need for complete release, tendon lengthening, or osteotomies in children younger than 8 years, with the soft tissues and bones still in a plastic state. The process of realignment can activate the growth plates, allowing joint congruity to be re-established with the foot aligned in a plantigrade position. The potential risks from excessive soft tissue stretching, however, are neurovascular damage, ischemia, skin necrosis and secondary infection
$[7-9,15,27,29,31]$. Because scar tissue is least expandable, distraction by the Ilizarov technique alone may be inadequate and subluxation of joints, lower tibia epiphysiolysis and claw toe deformities may occur $[8,12,13,16$, $18,20-22]$. These complications were not observed in our study, possibly because of open arthrolyses and tendon lengthening that reduced the deforming forces. Furthermore, the use of loops for magnification enabled careful anatomic dissection and protection of neurovascular structures and adherent tendons.

The Ilizarov technique, used in 7 feet that were not acutely corrected with the soft tissue release, allowed: (1) gradual correction to prevent neurovascular complications; (2) simultaneous three-dimensional, multilevel correction and (3) multiple levels of fixation to prevent tight soft tissues from deforming adjacent joints while correcting target joints [7, 10, 15]. This approach did not shorten the foot and probably allowed future remodeling.

The mean age of the seven patients undergoing correction with the Ilizarov technique was 7.7 years. We avoided osseous procedures. Four patients $(5,7,8,10$ of Table 1) were younger than 8 years of age. One of these patients (case 7) developed recurrence of forefoot adduction 3 years later, despite complete initial correction (Fig. 3). For the three patients who were older than 8 years, soft tissue procedures were selected since the recurrent deformities were classified as flexible (cases 3,9 of Table 1) (Fig. 4) or had already talonavicular arthritis and the treating surgeons decided to gradually correct the 


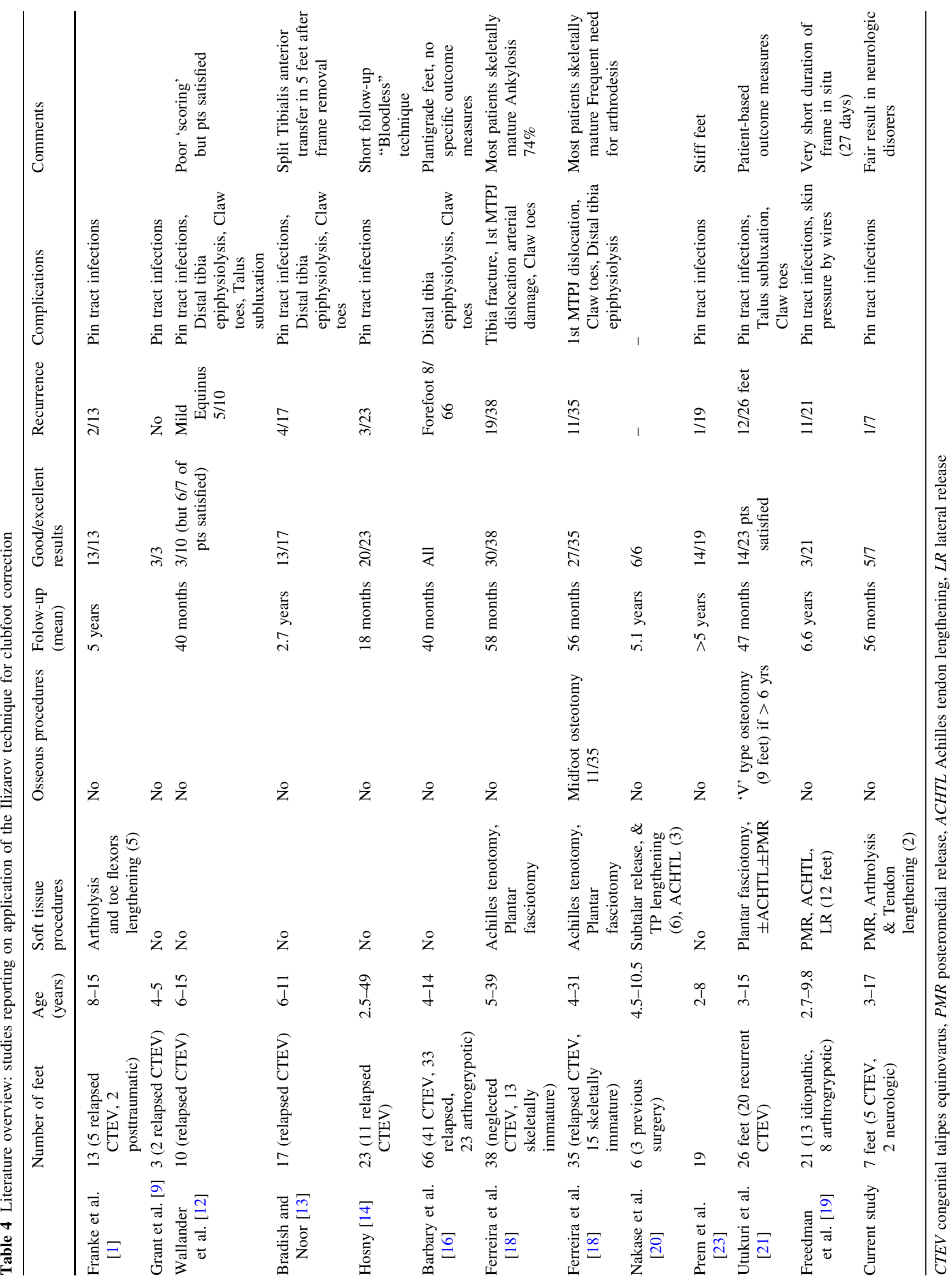


deformity by soft tissue distraction alone and to withhold the option of a triple fusion for the future (case 2).

A review of the literature revealed a few relatively small case series of Ilizarov treatment in relapsed clubfeet [8, 9, 12-14, 18-23] (Tables 3, 4). Results of treatment varied, with good/excellent outcomes ranging between 15 and $100 \%$, while recurrence rates $5-61 \%$ were reported. Most studies [8, 9, 13, 14, 16, 18, 20, 22, 23], reported good or excellent results in more than $75 \%$ of patients. All published reports, including the present study, have their limitations. Each series considers deformities of variable severity, etiology. Patients' age and treatment methods applied are not identical. Objective measurement of deformity and its correction are often quoted but overall outcome is difficult to standardize between papers as some authors use their own version of the 'excellent, good, fair, poor' system. Furthermore, there is no consensus for surgery outcome measures and functional scoring systems [18].

The current case series carries weaknesses, the most predominant being its retrospective nature, the small number of cases studied and the inclusion of both congenital and neurogenic clubfeet. However, since relapsed clubfoot deformity after surgical correction is an infrequent condition only small case series can be collected and mixture of aetiologies causing clubfoot are included in the majority of published papers. On the other hand, the current study includes patients treated by the same group of surgeons, applying constant principles in the management protocol. The selected Laaveg and Ponseti scale [25] used to evaluate our results, combines objective and subjective clinical parameters associated with the outcome of clubfoot surgery. On purpose, we did not use outcome measures incorporating radiographic measurements as they are difficult to be standardized and possibly unreliable [26]. Clear indications for the use of a ring external fixator and soft tissue or osseous procedures to correct relapsed clubfeet do not exist [15]. These patients may represent the severe end of a wide range of phenotypes and thus individualization of treatment for each patient may be justified. The application of the Ilizarov technique could safely supplement treatment. The proposed management for relapsed clubfeet aims at preservation of pain-free joints in an aligned foot for the young patients.

\section{Conclusion}

Deformity correction was possible even in older age when soft tissue procedures were combined with the use of Ilizarov technique, in order to support and gradually improve surgical correction.

\section{References}

1. Tachdjian M (1990) Pediatric orthopaedics, 2nd edn. WB Saunders, Philadelphia

2. Cowell HR, Wein BK (1980) Current concepts review genetic aspects of club foot. J Bone Joint Surg Am 62:1381-1384

3. Roye DP, Roye BD (2002) Idiopathic congenital talipes equinovarus. J Am Acad Orthop Surg 10:239-248

4. Davidson RS (2003) Clubfoot salvage: a review of the past decade's contributions. J Pediatr Orthop 23:410-418

5. Ippolito E, Farsetti P, Caterini R, Tudisco C (2006) Long-term comparative results in patients with congenital clubfoot treated with two different protocols. J Bone Joint Surg Am 85A:12861294

6. Dobbs MB, Nunley R, Schoenecker PL (2006) Long-term followup of patients with clubfeet treated with extended soft tissue release. J Bone Joint Surg Am 88A:986-996

7. Ilizarov GA (1989) The tension-stress effect on the genesis and growth of tissues. Part 1: the influence of stability of fixation and soft tissue preservation. Clin Orthop 238:249-281

8. Franke J, Grill F, Hein G, Simon M (1990) Correction of clubfoot relapse using Ilizarov's apparatus in children 8-15 years old. Arch Orthop Trauma Surg 110:33-37

9. Grant AD, Atar D, Lehman WB (1992) The Ilizarov technique in correction of complex foot deformities. Clin Orthop 280:94-103

10. Paley D (1993) The correction of complex foot deformities using Ilizarov's distraction osteotomies. Clin Orthop 293:97-111

11. Tetsworth KD, Paley D (1994) Accuracy of correction of complex lower extremity deformities by the Ilizarov method. Clin Orthop 301:102-110

12. Wallander H, Hansson G, Tjerstrom B (1996) Correction of persistent clubfoot deformities with the Ilizarov external fixator. Acta Orthop Scand 67:283-287

13. Bradish CF, Noor S (2000) The Ilizarov method in the management of relapsed clubfeet. J Bone Joint Surg Br 82B:387-391

14. Hosny GA (2002) Correction of foot deformities by the Ilizarov method without corrective osteotomies or soft tissue release. J Paediatr Orthop B 11:121-128

15. Gibbons CT, Montgomery RJ (2003) Management of foot and ankle conditions using Ilizarov technique. Current Orthopaedics $17: 436-446$

16. Barbary HE, Ghani HA, Hegazy M (2004) Correction of relapsed or neglected clubfoot using a simple Ilizarov frame. Int Orthop 28:183-186

17. Burns KJ, Sullivan R (2004) Correction of severe residual clubfoot deformity in adolescents with the Ilizarov technique. Foot Ankle Clin N Am 9:571-582

18. Ferreira RC, Costo MT, Frizzo MM, Filho FFF (2006) Correction of neglected clubfoot using the Ilizarov external fixator. Foot Ankle Int 27:266-273

19. Freedman JA, Watts H, Oisuka N (2006) The Ilizarov method for the treatment of resistant clubfoot: is it an effective solution? J Pediatr Orthop 26(4):432-437

20. Nakase T, Yasui N, Shimizu N, Yoshikawa H (2006) Tretament of relapsed idiopathic clubfoot y complete subtalar release combined with the Ilizarov method. J Foot Ankle Surg 45(5):337-341

21. Utukuri MM, Ramadrachan M, Hartley J, Hill RA (2006) Patientbased outcomes after Ilizarov surgery in resistant clubfeet. J Pediatr Orthop B 15(4):278-284

22. Ferreira RC, Costa MT, Frizzo GG, Santin RAL (2007) Correction of severe recurrent clubfoot using a simplified setting of the Ilizarov device. Foot Ankle Int 28:557-568

23. Prem H, Zenios M, Farrel R, Day JB (2007) Soft tissue Ilizarov correction of congenital talipes equinovarus, 5 to 10 years postsurgery. J Pediatr Orthop 27(2):220-224 
24. Conti SF, Kirschner JS, van Sickle D (2001) Midfoot ostetomies. Foot Ankle Clin N Am 6(3):519-532

25. Laaveg SJ, Ponseti IV (1980) Long-term results of treatment of congenital club foot. J Bone Joint Surg Am 62:23-31

26. Fridman MW, de Almeida Fialho HS (2006) The role of radiographic measurements in the evaluation of congenital clubfoot surgical results. Skeletal Radiol 36(2):129-138

27. Turco VJ (1979) Resistant congenital clubfoot: one-stage posteromedial release with internal fixation: a follow-up report of a fifteen-year experience. J Bone Joint Surg Am 61:805-814
28. Hutchins PM, Foster BK, Paterson DC, Cole EA (1985) Longterm results of early surgical release in club feet. J Bone Joint Surg Br 67:791-799

29. Carroll NC (1997) Clubfoot: what have we learned in the last quarter century? J Pediatr Orthop 17:1-2

30. Atar D, Lehman WH, Grant AD, Strongwater AM (1992) Revision surgery in clubfeet. Clin Orthop 283:223-230

31. McKay DW (1983) New concept of an approach to clubfoot treatment—evaluation and results. J Pediatr Orthop 3:141-148 